\title{
Idiopathic pulmonary hemosiderosis
}

INSERM

\section{Source}

INSERM. (1999). Orphanet: an online rare disease and orphan drug data base. Idiopathic pulmonary hemosiderosis. ORPHA:99931

Idiopathic pulmonary hemosiderosis is a respiratory disease due to repeated episodes of diffuse alveolar hemorrhage without any underlying apparent cause, most often in children. Anemia, cough, and pulmonary infiltrates on chest radiographs are found in majority of the patients. 